Check for updates

Cite this: RSC Adv., 2021, 11, 9048

Received 29th January 2021

Accepted 22nd February 2021

DOI: 10.1039/d1ra00781e

rsc.li/rsc-advances

\section{Bimetallic zeolite-imidazole framework-based heterostructure with enhanced photocatalytic hydrogen production activity $\uparrow$}

\author{
Nayab Arif, Ye-Zhan Lin, Kai Wang, Yi-Chuan Dou, Yu Zhang, Kui Li, (D) Shiquan Liu* \\ and Fu-Tian Liu
}

Bimetallic zeolite-imidazole frameworks with controllable flat band position, band gap and hydrogen evolution reaction characteristics were adopted as a photocatalytic hydrogen production catalyst. Furthermore, the $\mathrm{g}-\mathrm{C}_{3} \mathrm{~N}_{4}-\mathrm{MoS}_{2} 2 \mathrm{D}-2 \mathrm{D}$ surface heterostructure was introduced to the $\mathrm{ZnM}-\mathrm{ZIF}$ to facilitate the separation as well as utilization efficiency of the photo-exited charge carriers in the ZnMZIFs. On the other hand, the ZnM-ZIFs not only inhibited the aggregation of the $\mathrm{g}-\mathrm{C}_{3} \mathrm{~N}_{4}-\mathrm{MoS}_{2}$ heterostructure, but also improved the separation and transport efficiency of charge carriers in $\mathrm{g}-\mathrm{C}_{3} \mathrm{~N}_{4}-$ $\mathrm{MoS}_{2}$. Consequently, the optimal g- $\mathrm{C}_{3} \mathrm{~N}_{4}-\mathrm{MoS}_{2}-\mathrm{ZnNi}$-ZIF exhibited an extraordinary photocatalytic hydrogen evolution activity 214.4, 37.5, and 3.7 times larger than that of the pristine g- $\mathrm{C}_{3} \mathrm{~N}_{4}, \mathrm{~g}-\mathrm{C}_{3} \mathrm{~N}_{4}-$ $\mathrm{ZnNi}-\mathrm{ZIF}$ and g- $\mathrm{C}_{3} \mathrm{~N}_{4}-\mathrm{MoS}_{2}$, respectively, and exhibited a $\mathrm{H}_{2}$-evolution performance of $77.8 \mu \mathrm{mol} \mathrm{h}{ }^{-1}$ $\mathrm{g}^{-1}$ under UV-Vis light irradiation coupled with oxidation of $\mathrm{H}_{2} \mathrm{O}$ into $\mathrm{H}_{2} \mathrm{O}_{2}$. This work will furnish a new MOF candidate for photocatalysis and provide insight into better utilization of porous MOF-based heterostructures for hydrogen production from pure water.

\section{Introduction}

The direct conversion of sustainable solar power into ecofriendly energy over high performance photocatalysts has been extremely significant for powering human society. ${ }^{1-7}$ Up to now, it is universally recognized that the serious recombination, underutilization and poor transport of photon-generated carriers weaken the photocatalytic activity of the photocatalyst. ${ }^{8-12}$ Consequently, extensive efforts have been devoted to constructing heterostructures or phase junctions, which could increase the specific surface area of the photocatalyst, ${ }^{2,13-21}$ and adopting a suitable cocatalyst for improving the separation, transport and utilization of the photo-induced charge carriers. ${ }^{10,11,22,23}$ However, most of the photocatalyst systems were composed of inorganic metal oxides/sulfides, which may result in poor transport and separation efficiency of charge carriers, low porosity, and limited flexibility in material design. In this instance, metal-organic frameworks (MOFs), constructed from metal ions/clusters and organic linkers, exhibited various attractive characteristics such as high specific surface area, crystalline nature, ${ }^{24-26}$ and especially structure diversity for easy tailorability of the functionality, ${ }^{24,27-29}$ and have attracted widespread interest in photocatalytic

School of Materials Science and Engineering, University of Jinan, Jinan 250022, China. E-mail:mse_lik@ujn.edu.cn; vctrliu@hotmail.com

$\dagger$ Electronic supplementary information (ESI) available. See DOI: 10.1039/d1ra00781e applications. Hence, various Zr, Ti, Cr-based MOFs with and without Pt, small molecular and even polyoxometalates (POMs) have been extensively investigated as photocatalyst for hydrogen production. . $5,26,30,31^{2}$

As one of the most stable metal organic frameworks in neutral and alkaline solutions, ${ }^{26,32,33}$ Zeolite Imidazole Frameworks (ZIFs) and its heterostructure has been extensively studied for the photocatalytic reaction. ${ }^{33,34}$ Especially, the bimetallic ZIFs has been widely investigated because it possesses various structures, has versatile functions and its photo-electric properties. Moreover, the bimetallic ZIF derived nanomaterials have been fabricated and used in the electrocatalytic energy conversion and storage..$^{25,32,34-36}$ However, the bimetallic ZIFs itself with special merits for photocatalysis was rarely reported as photocatalyst, although this is a stirring work, and will bring out some new interesting prospects. Moreover, almost all the MOFs photocatalysts suffered from the problems of limited photocatalytic hydrogen production activity and poor photocatalytic stability even in sacrificial agent solution owing to the low photo-response, rapid recombination of photo-exited electron-hole pairs. Construction of ZIFs-based heterostructure not only resolved the problems of low porosity of semiconductors, but also improved the separation and utilization of the photo-generated charge carriers.

Graphic carbon nitride $\left(\mathrm{g}-\mathrm{C}_{3} \mathrm{~N}_{4}\right)$, which is composed of the earth abundant carbon and nitrogen atoms through strong covalent bonds, possesses enhanced stability in solutions over a wide $\mathrm{pH}$ range, and suitable for the visible light 
absorption. ${ }^{37-40}$ The separation and utilization efficiency of the photo-generated charge carriers in $\mathrm{g}-\mathrm{C}_{3} \mathrm{~N}_{4}$ is very limited, resulting in poor photocatalytic activity., ${ }^{\mathbf{9} 23,41}$ Consequently, a large number of cocatalysts were fabricated, and one of the most extensively investigated cocatalyst is $\operatorname{MoS}_{2} \cdot{ }^{\mathbf{9} 42-45}$ Due to the different work function of $\mathrm{MoS}_{2}$ compared with the semiconductor components, and its low hydrogen evolution reaction (HER) overpotential, the photo-exited electrons and holes in g$\mathrm{C}_{3} \mathrm{~N}_{4}-\mathrm{MoS}_{2}$ 2D-2D surface heterostructure could be transformed into different semiconductor components with high utilization efficiency. Therefore $\mathrm{g}-\mathrm{C}_{3} \mathrm{~N}_{4}-\mathrm{MoS}_{2}$ heterostructure was adopted to incorporate on ZIFs-based heterostructure that not only resolved the problems of low porosity, but also improved the separation and utilization of the photo-generated charge carriers between $\mathrm{g}-\mathrm{C}_{3} \mathrm{~N}_{4}-\mathrm{MoS}_{2}-\mathrm{ZnM}-\mathrm{ZIF}$. Simultaneously, ZnM-ZIF could restrain the agglomeration of $\mathrm{g}-\mathrm{C}_{3} \mathrm{~N}_{4}-$ $\mathrm{MoS}_{2}$ during the subsequent post annealing and photocatalytic reactions. ${ }^{\mathbf{9 , 4 6 , 4 7}}$ However, during the fabrication process and/or the photocatalytic reaction, the $\mathrm{g}-\mathrm{C}_{3} \mathrm{~N}_{4}-\mathrm{MoS}_{2}$ nanosheet may aggregate occur and thus deteriorate its photocatalytic hydrogen production activity. ${ }^{\mathbf{3 4 , 4 8}}$ Moreover, the photocatalytic hydrogen evolution in pure water for $\mathrm{g}-\mathrm{C}_{3} \mathrm{~N}_{4}-\mathrm{MoS}_{2}$ and especially MOFs photocatalyst is important and it also faces huge challenges. $^{49}$

Herein, bimetallic ZIFs (ZnM-ZIF, M $=$ Co, Ni) with controllable band were synthesized and adopted as the photocatalytic hydrogen production catalyst with a considerable photocatalytic HER activity. The g- $\mathrm{C}_{3} \mathrm{~N}_{4}-\mathrm{MoS}_{2}$ nanorods were prepared by one-step hydrothermal method. Further the g$\mathrm{C}_{3} \mathrm{~N}_{4}-\mathrm{MoS}_{2}-\mathrm{ZnM}$-ZIFs ( $\mathrm{M}=\mathrm{Co}, \mathrm{Ni}$ ) were prepared using the similar method with $\mathrm{g}-\mathrm{C}_{3} \mathrm{~N}_{4}-\mathrm{MoS}_{2}$ as precursor. The introduction of $\mathrm{g}-\mathrm{C}_{3} \mathrm{~N}_{4}-\mathrm{MoS}_{2}$ onto the surface of the ZnM-ZIF not only improved the utilization efficiency of photo-exited charge carriers by $\mathrm{MoS}_{2}$, but also inhibited the accumulation of $\mathrm{g}$ $\mathrm{C}_{3} \mathrm{~N}_{4}-\mathrm{MoS}_{2}$ heterostructure. Hence, the optimal g- $\mathrm{C}_{3} \mathrm{~N}_{4}-\mathrm{MoS}_{2}-$ ZnNi-ZIF (CNMZN) exhibited the extraordinary photocatalytic HER activity of $30.1 \mu \mathrm{mol} \mathrm{h}{ }^{-1}$, being $214.4,37.5$, and 3.7 times larger than that of the pristine g- $\mathrm{C}_{3} \mathrm{~N}_{4}(\mathrm{CN}), \mathrm{g}-\mathrm{C}_{3} \mathrm{~N}_{4}-\mathrm{ZnNi}-\mathrm{ZIF}$ (CNZN) and $\mathrm{g}-\mathrm{C}_{3} \mathrm{~N}_{4}-\mathrm{MoS}_{2}$ (CNM), respectively. More importantly, even in pure water, the optimal ternary heterostructures exhibited considerable hydrogen production rate. This work provided innovation that can hopefully help in designing a novel high-performance MOF-based heterostructure photocatalyst for solar conversion.

\section{Experimental section}

\section{Materials and general methods}

$\mathrm{C}_{3} \mathrm{~N}_{3}\left(\mathrm{NH}_{2}\right)_{3}, \mathrm{Zn}\left(\mathrm{NO}_{3}\right)_{2} \cdot 6 \mathrm{H}_{2} \mathrm{O}, \mathrm{Ni}\left(\mathrm{NO}_{3}\right)_{2} \cdot 6 \mathrm{H}_{2} \mathrm{O}, \mathrm{Co}\left(\mathrm{NO}_{3}\right)_{2} \cdot 6 \mathrm{H}_{2} \mathrm{O}$, $\mathrm{C}_{4} \mathrm{H}_{6} \mathrm{~N}_{2}, \mathrm{H}_{3} \mathrm{P}\left(\mathrm{Mo}_{3} \mathrm{O}_{10}\right)_{4} \cdot x \mathrm{H}_{2} \mathrm{O}$ and $\mathrm{CH}_{4} \mathrm{~N}_{2} \mathrm{~S}$ (Shanghai Macklin Biochemical Technology Co., Ltd) are analytical grade and used as received without further purification. The powder X-ray diffraction (PXRD) patterns were recorded on a D/max 2500 $\mathrm{VL} / \mathrm{PC}$ diffractometer (Japan) equipped with graphite monochromatized $\mathrm{Cu} \mathrm{K} \alpha$ radiation $(\lambda=1.54060 \AA)$. Corresponding work voltage and current is $40 \mathrm{kV}$ and $100 \mathrm{~mA}$, respectively. The transmission electron microscopy (TEM) and high-resolution
TEM (HRTEM) images were recorded on JEOL-2100F apparatus at an accelerating voltage of $200 \mathrm{kV}$. The atomic structure of the $\mathrm{g}-\mathrm{C}_{3} \mathrm{~N}_{4}-\mathrm{MoS}_{2}$-MOF heterojunction was characterized using an ARM-200CF (JEOL, Tokyo, Japan) transmission electron microscope operated at $200 \mathrm{kV}$ and equipped with double spherical aberration correctors. Surface morphologies of the phase junction materials were examined by a scanning electron microscope (SEM, JSM-7600F) at an acceleration voltage of 10 $\mathrm{kV}$. The UV-Vis absorption and diffused reflectance spectra were recorded using a Cary 5000 UV-Vis spectrometer (Viarian, USA) with $\mathrm{BaSO}_{4}$ as a reflectance standard. Nitrogen adsorptiondesorption isotherms were measured at $77 \mathrm{~K}$ on a Quantachrome Instruments Autosorb AS-6B. The pore size distributions were measured by the Barrett-Joyner-Halenda (BJH) method. Steady photoluminescence (PL) emission spectra were tested by a luminescence spectrophotometer (QM-400, PTI) with $350 \mathrm{~nm}$ excitation wavelength. The transient photocurrent responses experiments were carried out at room temperature under visible light irradiation using a conventional three-electrode system with a glassy carbon electrode $(3 \mathrm{~mm}$ in diameter, sheet resistance 20-25 $\Omega$ per square) as the working electrode, a carbon rod as the auxiliary electrode, and an $\mathrm{Ag} / \mathrm{AgCl}$ electrode as the reference electrode. All the samples were dispersed in deionized water with a concentration of $1.5 \mathrm{mg} \mathrm{mL}^{-1}$ and deposited on the glassy carbon electrode and dried under visible light irradiation. The electrocatalytic hydrogen evolution reaction was measured in $1 \mathrm{M} \mathrm{KOH}$ solution. EIS data were recorded using electrochemical (Bio-Logic SP-150) workstation in $\mathrm{Na}_{2} \mathrm{SO}_{4}(0.5$ $\mathrm{M})$ solution. The transient photocurrent responses measurements were performed with a CHI 660E electrochemical station (Shanghai Chenhua Co. Ltd, China) under irradiation in $0.5 \mathrm{M}$ $\mathrm{Na}_{2} \mathrm{SO}_{4}$ solutions.

\section{Synthesis of $\mathrm{g}-\mathrm{C}_{3} \mathrm{~N}_{4}$}

The pure $\mathrm{g}-\mathrm{C}_{3} \mathrm{~N}_{4}$ photocatalyst was prepared by a traditional thermal polymerization strategy. In a typical procedure, $5 \mathrm{~g}$ of $\mathrm{C}_{3} \mathrm{~N}_{3}\left(\mathrm{NH}_{2}\right)_{3}$ was placed in a crucible with a cover, and then it was annealed at $650{ }^{\circ} \mathrm{C}$ for $2 \mathrm{~h}$ in the argon. The final yellow powder was then collected.

\section{Synthesis of the g- $\mathrm{C}_{3} \mathrm{~N}_{4}-\mathrm{MoS}_{2}$}

The $\mathrm{g}-\mathrm{C}_{3} \mathrm{~N}_{4}-\mathrm{MoS}_{2}$ nanorods were prepared using $\mathrm{H}_{3} \mathrm{P}\left(\mathrm{Mo}_{3}\right.$ $\left.\mathrm{O}_{10}\right)_{4} \cdot x \mathrm{H}_{2} \mathrm{O}, \mathrm{CH}_{4} \mathrm{~N}_{2} \mathrm{~S}$ as precursors by one-step hydrothermal method. In a typical procedure, $200 \mathrm{mg}$ g- $\mathrm{C}_{3} \mathrm{~N}_{4}$, suitable amount of $\mathrm{H}_{3} \mathrm{P}\left(\mathrm{Mo}_{3} \mathrm{O}_{10}\right)_{4} \cdot x \mathrm{H}_{2} \mathrm{O}$ (with Mo content of $6 \mathrm{wt} \%(19 \mathrm{mg})$ in comparison with $\mathrm{g}-\mathrm{C}_{3} \mathrm{~N}_{4}$ ) and $\mathrm{CH}_{4} \mathrm{~N}_{2} \mathrm{~S}$ (the corresponding ratios of $\mathrm{Mo} / \mathrm{S}$ equal to $1: 2$ ) were dissolved in $30 \mathrm{~mL}$ distilled water. The solutions were subsequently transferred into $50 \mathrm{~mL}$ Teflonlined autoclave and maintained for $24 \mathrm{~h}$ at $160{ }^{\circ} \mathrm{C}$. The final black products were rinsed three times with distilled water and ethanol respectively, and dried at $60{ }^{\circ} \mathrm{C}$ for overnight in a vacuum oven to evaporate the solvent.

\section{Synthesis of the ZnNi-MOF, ZnCo-MOF and ZIF-8}

The $\mathrm{ZnNi}-\mathrm{MOF}$ nanorods were prepared using $\mathrm{Zn}\left(\mathrm{NO}_{3}\right)_{2} \cdot 6 \mathrm{H}_{2} \mathrm{O}$, $\mathrm{Ni}\left(\mathrm{NO}_{3}\right)_{2} \cdot 6 \mathrm{H}_{2} \mathrm{O}$ and $\mathrm{C}_{4} \mathrm{H}_{6} \mathrm{~N}_{2}$ as precursors, an amount of 
$\mathrm{Zn}\left(\mathrm{NO}_{3}\right)_{2} \cdot 6 \mathrm{H}_{2} \mathrm{O}$ and $\mathrm{Ni}\left(\mathrm{NO}_{3}\right)_{2} \cdot 6 \mathrm{H}_{2} \mathrm{O}$ (the corresponding ratios of $\mathrm{Zn} / \mathrm{Ni}$ equal to $1: 9,3: 7,5: 5,7: 3,9: 1$ ) were dissolved into $20 \mathrm{~mL}$ distilled water. The mole number of $\mathrm{C}_{4} \mathrm{H}_{6} \mathrm{~N}_{2}$ was 10 times larger than that of the sum molar number of $\mathrm{Zn}\left(\mathrm{NO}_{3}\right)_{2} \cdot 6 \mathrm{H}_{2} \mathrm{O}$ and $\mathrm{Ni}\left(\mathrm{NO}_{3}\right)_{2} \cdot 6 \mathrm{H}_{2} \mathrm{O}$, these precursors were dissolved into $10 \mathrm{~mL}$ distilled water. Thereafter, the $\mathrm{C}_{4} \mathrm{H}_{6} \mathrm{~N}_{2}$ solution was added dropwise into the above mixture solution while stirring. The final mixture was stirred for $24 \mathrm{~h}$ at room temperature. The precipitates were rinsed with deionized water and anhydrous ethanol several times, and then dried in a vacuum oven at $60^{\circ} \mathrm{C}$ for $12 \mathrm{~h}$. The ZIF-8 and ZnCo-MOF could be obtained by replacing the $\mathrm{Ni}\left(\mathrm{NO}_{3}\right)_{2} \cdot 6 \mathrm{H}_{2} \mathrm{O}$ with $\mathrm{Zn}\left(\mathrm{NO}_{3}\right)_{2} \cdot 6 \mathrm{H}_{2} \mathrm{O}$ and $\mathrm{Co}\left(\mathrm{NO}_{3}\right)_{2} \cdot 6 \mathrm{H}_{2} \mathrm{O}$, respectively.

\section{Synthesis of the g- $\mathrm{C}_{3} \mathrm{~N}_{4}-\mathrm{ZnM}$-ZIFs and g- $\mathrm{C}_{3} \mathrm{~N}_{4}-\mathrm{MoS}_{2}-\mathrm{ZnM}-$ ZIFs}

Suitable amount of $\mathrm{Zn}\left(\mathrm{NO}_{3}\right)_{2} \cdot 6 \mathrm{H}_{2} \mathrm{O}$ and $\mathrm{Ni}\left(\mathrm{NO}_{3}\right)_{2} \cdot 6 \mathrm{H}_{2} \mathrm{O}$ (the corresponding ratios of $\mathrm{Zn} / \mathrm{Ni}$ equal to $5: 5$ ) and as-prepared $\mathrm{g}$ $\mathrm{C}_{3} \mathrm{~N}_{4}$ were added into $20 \mathrm{~mL}$ distilled water. $\mathrm{C}_{4} \mathrm{H}_{6} \mathrm{~N}_{2}$ with 10 mole ratios of the amount of $\mathrm{Zn}\left(\mathrm{NO}_{3}\right)_{2} \cdot 6 \mathrm{H}_{2} \mathrm{O}$ and $\mathrm{Ni}\left(\mathrm{NO}_{3}\right)_{2}-$ $\cdot 6 \mathrm{H}_{2} \mathrm{O}$ were dissolved into $10 \mathrm{~mL}$ distilled water. Thereafter, the $\mathrm{C}_{4} \mathrm{H}_{6} \mathrm{~N}_{2}$ solution was added dropwise into the above mixture solution while stirring. The final mixture was stirred for $24 \mathrm{~h}$ at room temperature. The precipitates were rinsed with deionized water and anhydrous ethanol several times, and then dried in a vacuum oven at $60^{\circ} \mathrm{C}$ for $12 \mathrm{~h}$. The g- $\mathrm{C}_{3} \mathrm{~N}_{4}-\mathrm{ZIF}-8$ and g- $\mathrm{C}_{3} \mathrm{~N}_{4}-$ ZnCo-ZIF could be obtained by replacing the $\mathrm{Ni}\left(\mathrm{NO}_{3}\right)_{2} \cdot 6 \mathrm{H}_{2} \mathrm{O}$ by $\mathrm{Co}\left(\mathrm{NO}_{3}\right)_{2} \cdot 6 \mathrm{H}_{2} \mathrm{O}$. The $\mathrm{g}-\mathrm{C}_{3} \mathrm{~N}_{4}-\mathrm{MoS}_{2}-\mathrm{ZnM}$-ZIFs were prepared using the similar method with $\mathrm{g}-\mathrm{C}_{3} \mathrm{~N}_{4}-\mathrm{MoS}_{2}$ as precursor as shown in Fig. 1a.

\section{Photocatalytic hydrogen production}

The photocatalytic $\mathrm{H}_{2}$-production experiments were performed via photocatalytic $\mathrm{H}_{2}$-production activity evaluation system (CEL-SPH2N, CEAU-Light, China) in a $300 \mathrm{~mL}$ Pyrex flask, and the flask openings were sealed with silicone rubber septum. A $300 \mathrm{~W}$ xenon arc lamp was used as all light source, and was positioned $13 \mathrm{~cm}$ away from the reaction solution to trigger the photocatalytic reaction. A $300 \mathrm{~W}$ xenon arc lamp through a UVcutoff filter $(\lambda=420-800 \mathrm{~nm})$ was used as a visible light source, and was positioned $13 \mathrm{~cm}$ away from the reaction solution to trigger the photocatalytic reaction. FZ-A visible-light radiometer (made in the photoelectric instrument factory of Beijing Normal University, China) was used to measure the focused intensity on the flask (i.e., $200 \mathrm{~mW} \mathrm{~cm}{ }^{-2}$ ). In a typical photocatalytic $\mathrm{H}_{2}$ production experiment, $20 \mathrm{mg}$ of the as-prepared photocatalyst was suspended in $50 \mathrm{~mL}$ of mixed aqueous solution of $5 \mathrm{~mL}$ $\mathrm{C}_{6} \mathrm{H}_{15} \mathrm{NO}_{3}$ (AR, 98\%). To ensure the anaerobic condition in the reactor before irradiation, the system was vacuumed for $5 \mathrm{~min}$ by the use of vacuum pump for the entire removal of dissolved oxygen. The photocatalyst particles were suspended throughout the experiments by employing a continuous magnetic stirrer at the bottom of the reactor. $\mathrm{H}_{2}$ content was analyzed by gas chromatography (GC-7900, CEAU-Light, China). All glassware were carefully rinsed with DI water prior to usage. The photocatalytic stability was also performed in the same processing
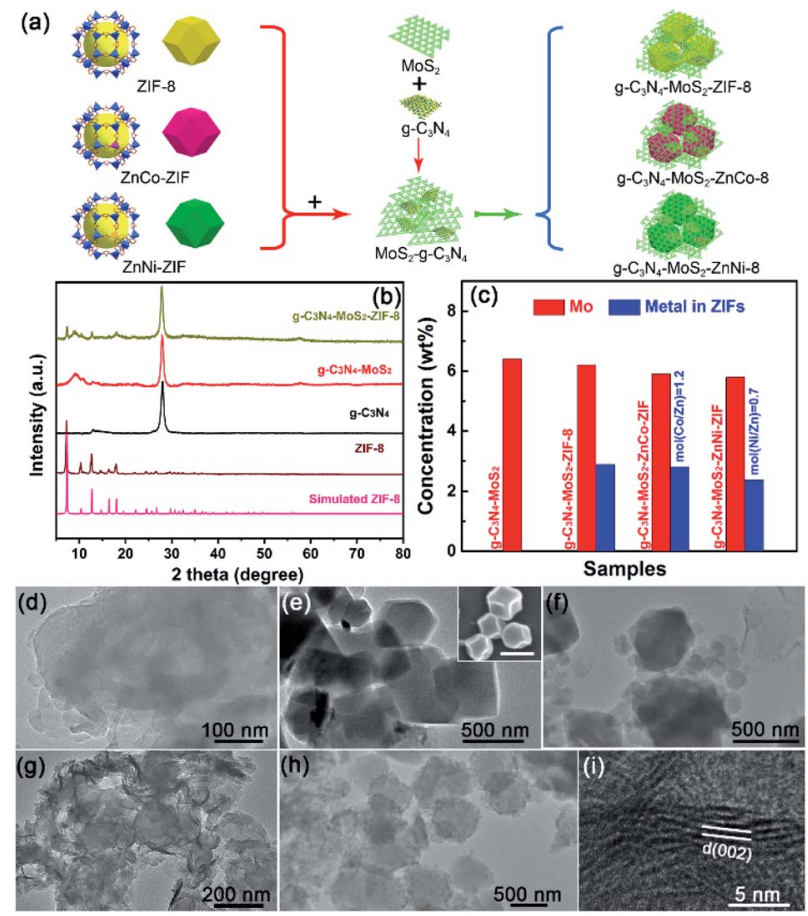

Fig. 1 (a) Scheme illustrating the synthesis of the ternary $g-\mathrm{C}_{3} \mathrm{~N}_{4}-$ $\mathrm{MoS}_{2}-\mathrm{ZnNi}$-ZIF heterostructure. (b) PXRD patterns of the $\mathrm{g}-\mathrm{C}_{3} \mathrm{~N}_{4}$, g$\mathrm{C}_{3} \mathrm{~N}_{4}-\mathrm{MoS}_{2}, \mathrm{~g}-\mathrm{C}_{3} \mathrm{~N}_{4}-\mathrm{MoS}_{2}-\mathrm{ZIFs}$ and ZIF-8 (c) Mo and metals concentrations in the $\mathrm{g}-\mathrm{C}_{3} \mathrm{~N}_{4}-\mathrm{MoS}_{2}$ and $\mathrm{g}-\mathrm{C}_{3} \mathrm{~N}_{4}-\mathrm{MoS}_{2}$-ZIFs from ICP spectroscope. TEM images of the (d) $\mathrm{g}-\mathrm{C}_{3} \mathrm{~N}_{4}$, (e) $\mathrm{ZnNi}$-ZIF (inset showing the SEM image), (f) $g-C_{3} N_{4}-Z n N i-Z I F$, (g) g- $C_{3} N_{4}-M_{0} S_{2}$ (h) g- $\mathrm{C}_{3} \mathrm{~N}_{4}-\mathrm{MoS}_{2}-\mathrm{ZnNi}-\mathrm{ZIF}$, and (i) HRTEM image of the $\mathrm{g}-\mathrm{C}_{3} \mathrm{~N}_{4}-\mathrm{MoS}_{2}-$ $\mathrm{ZnNi}-\mathrm{ZIF}$

parameters. Every $12 \mathrm{~h}$ the sacrificial regent was renewed for the evaluation of the photocatalytic stability in vacuum.

\section{Results and discussion}

The powder X-ray diffraction patterns (PXRD) of $\mathrm{g}-\mathrm{C}_{3} \mathrm{~N}_{4}$ with $\mathrm{MoS}_{2}$ and/or ZnM-ZIF is demonstrated in Fig. 1b. The characteristic diffraction peaks of g- $\mathrm{C}_{3} \mathrm{~N}_{4}-\mathrm{MoS}_{2}$-ZIFs could be clearly observed. For comparison, g- $\mathrm{C}_{3} \mathrm{~N}_{4}$-based samples with and without $\mathrm{MoS}_{2}$ is shown in Fig. 1b, the diffraction peak of the $\mathrm{MoS}_{2}$ (around $9^{\circ}$ ) shifted to lower theta values (around $1^{\circ}$ ) due to the larger interplanar spacing, verifying the successful fabrication of ternary g- $\mathrm{C}_{3} \mathrm{~N}_{4}-\mathrm{MoS}_{2}-\mathrm{ZnM}$-ZIF heterostructure as shown in Fig. $1 \mathrm{~b}$ and $\mathrm{S} 1, \dagger$ and has been previously reported..$^{50}$ Notably, PXRD pattern justified the successful g- $\mathrm{C}_{3} \mathrm{~N}_{4}-\mathrm{ZnM}$ $\mathrm{ZIF}-\mathrm{MoS}_{2}$ heterostructure formation at first and then reduction of peak shows that material after hetero-structure composite is 2D material which is amorphous in nature. Furthermore, Fourier Transform Infrared Spectroscopy (FTIR) spectra were further employed for confirming the formation of $\mathrm{g}-\mathrm{C}_{3} \mathrm{~N}_{4}-\mathrm{ZnM}$ ZIF heterostructures. As shown in Fig. S2a, $\uparrow$ the typical peak of ZnNi-ZIF appeared at $422 \mathrm{~cm}^{-1}$ belonged to the Ni-N stretching vibration, the peaks at 2960 and $2925 \mathrm{~cm}^{-1}$ could be attributed to the asymmetric absorption vibration of the $\mathrm{C}-\mathrm{H}$ bond in the $-\mathrm{CH}_{3}$ group, the absorption peaks at $748 \mathrm{~cm}^{-1}$ was caused by 
stretching vibration of the $\mathrm{C}=\mathrm{N}$ bond in 2-methylimidazole, and the intense absorption peaks at $1000 \mathrm{~cm}^{-1}$ were derived from the plane bending vibration of the imidazole ring. ${ }^{51}$ Distinctly, the characteristic FTIR peaks of ZnM-ZIF and g- $\mathrm{C}_{3} \mathrm{~N}_{4}$ could also be clearly observed in the $\mathrm{g}-\mathrm{C}_{3} \mathrm{~N}_{4}-\mathrm{MoS}_{2}-\mathrm{ZIF}-8$ (CNMZ) and $\mathrm{g}-\mathrm{C}_{3} \mathrm{~N}_{4}-\mathrm{MoS}_{2}-\mathrm{ZnCo}-\mathrm{ZIF}$ (CNMZC) samples (Fig. S2b $\dagger$ ), verifying the existence of ZnM-ZIF in the $\mathrm{g}-\mathrm{C}_{3} \mathrm{~N}_{4}-$ $\mathrm{MoS}_{2}$-ZnM-ZIF. The concentrations of Mo and the metals in ZnM-ZIFs in the g- $\mathrm{C}_{3} \mathrm{~N}_{4}-\mathrm{MoS}_{2}$ with and without ZnM-ZIFs were investigated via inductively coupled plasma (ICP) spectroscope (Fig. 1c). The Mo content in the relevant samples was very close to the theory predicted value. Whereas, the metals content in the ZnM-ZIFs was lower than the given value (10 wt\%), which may be attributed to the underreaction between the metals and ligand. Moreover, the molar ratio of the $\mathrm{Zn} / \mathrm{Co}$ and $\mathrm{Zn} / \mathrm{Ni}$ was close the supposed value, which indicates that the synthesized bimetallic ZIF meets expectations.

Transmission electron microscopy (TEM) was employed for investigating the morphology of the $\mathrm{g}-\mathrm{C}_{3} \mathrm{~N}_{4}$ embedded with ZnM-ZIF and/or $\mathrm{MoS}_{2}$. The dense nanosheet morphology of pristine $\mathrm{g}-\mathrm{C}_{3} \mathrm{~N}_{4}$ could be observed in Fig. $1 \mathrm{~d}$, and compared with ZIF-8 and ZnNi-ZIFs, the as-prepared ZnNi-ZIF exhibited regular truncated rhombic dodecahedron structure as confirmed by the TEM and scanning electron microscope (SEM) images (Fig. 1e and $\mathrm{S} 3 \mathrm{a}-\mathrm{c} \dagger)$. For the $\mathrm{CNZN}$, the microstructure of $\mathrm{g}-\mathrm{C}_{3} \mathrm{~N}_{4}$ nanosheet enwrapped MOF blocks is clearly observable, proved the formation of CNZN surface heterostructure (Fig. 1f), which was further confirmed by the SEM images of $\mathrm{g}-\mathrm{C}_{3} \mathrm{~N}_{4}-\mathrm{ZnM}$-ZIFs as depicted in Fig. S3d-f. $\dagger$ The CNM was a 2D-2D surface heterostructure (Fig. 1g) as reported in the previous publication. ${ }^{50}$ Notably, the CNM nanosheet was distributed uniformly over the surface of ZnNi-ZIF as demonstrated in Fig. 1h, and the (002) lattice plane of $\mathrm{MoS}_{2}$ could be clearly observed from CNMZN (Fig. 1i), which has an enlarged interlayer spacing $(0.95 \mathrm{~nm})$. Moreover, the $\mathrm{g}-\mathrm{C}_{3} \mathrm{~N}_{4}-\mathrm{MoS}_{2}-\mathrm{ZnM}$-ZIFs exhibited similar morphology on SEM images (Fig. S3g-i†). Further adopted the elemental mapping to investigate the distribution of different components in the ternary CNMZN (Fig. S4 $\dagger$ ). The result confirmed that all the $\mathrm{C}, \mathrm{N}, \mathrm{Zn}, \mathrm{Ni}, \mathrm{S}$ and Mo uniformly dispersed. Further verifying both the $\mathrm{MoS}_{2}$ and $\mathrm{g}-\mathrm{C}_{3} \mathrm{~N}_{4}$ distributed evenly on the skeleton of $\mathrm{ZnNi}$-ZIF.

The visible light absorption and the bandgap of the asprepared $\mathrm{g}-\mathrm{C}_{3} \mathrm{~N}_{4}$-based heterostructures were investigated via the UV-Vis diffuse absorption spectra (Fig. 2a). After embedding ZnM-ZIFs, the absorption of the $\mathrm{g}-\mathrm{C}_{3} \mathrm{~N}_{4}$ in the visible light region has a little enhancement (Fig. S5 $\dagger$ ), while for the $g-\mathrm{C}_{3} \mathrm{~N}_{4}-$ $\mathrm{MoS}_{2}$, the absorption rate is significantly improved (Fig. S6 $\dagger$ ). It is worth noting that the co-loading of the $\mathrm{MoS}_{2}$ and ZnM-ZIF exhibited a synergistic effect for the absorption of visible light, and the absorption intensity in the visible light region was in the order of CNMZC > CNMZN $>$ ZNMZ. The bandgaps of g$\mathrm{C}_{3} \mathrm{~N}_{4}$ and $\mathrm{MoS}_{2}$ calculated according to the Kubelka-Munk (KM) method are 2.74 and $1.67 \mathrm{eV}$ (Fig. 2b).$^{52,53}$ As displayed in Fig. 2c, simultaneous doping of $\mathrm{Co}$ and $\mathrm{Ni}$ could increase the visible light absorption capacity of ZIF-8, as further confirmed by the bandgaps for ZIF-8, ZnCo-ZIF and ZnNi-ZIF of 5.1, 2.3 and 2.0, respectively (Fig. 2d). To determine the band structure
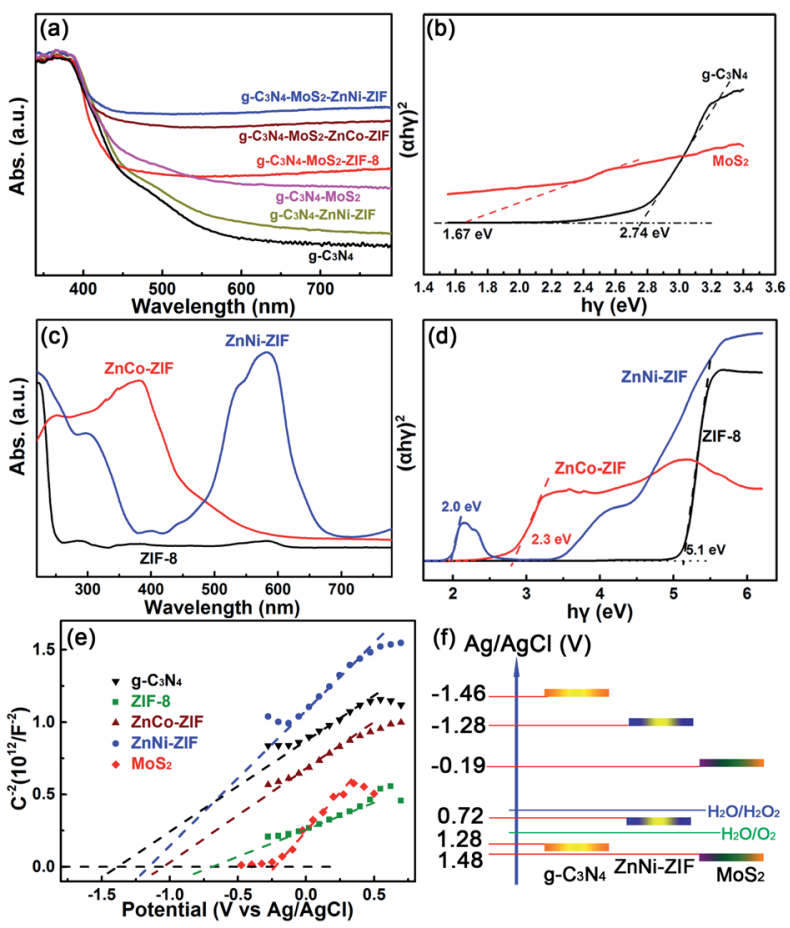

Fig. 2 The UV-Vis absorption spectra and $(\alpha h \nu)^{2}$ versus $h \nu$ curves of (a and b) g- $\mathrm{C}_{3} \mathrm{~N}_{4}$ loaded with $\mathrm{MoS}_{2}$ and/or ZnM-ZIF, and (c and d) ZnMZIFs. The (e) Mott-Schottky plots of the $\mathrm{g}-\mathrm{C}_{3} \mathrm{~N}_{4}, \mathrm{MoS}_{2}$ and the $\mathrm{ZnM}$ $\mathrm{ZIF}$, and (f) the band structure matching in the ternary g- $\mathrm{C}_{3} \mathrm{~N}_{4}-\mathrm{MoS}_{2}-$ ZnNi-ZIF heterostructure.

matching and charge separation mechanism among $\mathrm{g}-\mathrm{C}_{3} \mathrm{~N}_{4}$, $\mathrm{MoS}_{2}$, and ZnM-ZIFs, the Mott-Schottky plot measurements were used to investigate the flat band potential of them. As shown in Fig. 2e, the ZIF-8, ZnCo-ZIF, and ZnNi-ZIF exhibited flat-band potentials of $-0.89,-1.24$ and $-1.28 \mathrm{~V} v s$. $\mathrm{Ag} / \mathrm{AgCl}$, respectively, which were lower than that of the pristine $\mathrm{g}-\mathrm{C}_{3} \mathrm{~N}_{4}$ $(-1.46 \mathrm{~V})$, while higher than that of $\mathrm{MoS}_{2}(-0.19 \mathrm{~V})$. Therefore, the band structure matching in the ternary g- $\mathrm{C}_{3} \mathrm{~N}_{4}-\mathrm{MoS}_{2}-\mathrm{ZnNi}$ ZIF heterostructure could be inferred in Fig. 2f. This band structure indicated the transfer of photo-generated electron from the conduction band (CB) of $\mathrm{g}-\mathrm{C}_{3} \mathrm{~N}_{4}$ and $\mathrm{ZnNi}$-ZIFs to that of $\mathrm{MoS}_{2}$. On the other hand, the holes were transferred into the valence band (VB) of ZnNi-ZIF, where the $\mathrm{H}_{2} \mathrm{O}_{2}$ was preferentially formed efficiently owing to the highly porous morphology of $\mathrm{ZnNi}$-ZIF. The band structure matching of the $\mathrm{g}-\mathrm{C}_{3} \mathrm{~N}_{4}-\mathrm{ZnNi}-$ $\mathrm{MoS}_{2}$ not only facilitated the separation and utilization efficiency, but also improved the visible light absorption between $\mathrm{g}$ $\mathrm{C}_{3} \mathrm{~N}_{4}$, ZnNi-ZIF and $\mathrm{MoS}_{2}$.

Notably, in sharply contrast to the negligible photocatalytic hydrogen production activity of ZIF- 8 because of its large bandgap (5.1 eV), the bare bimetallic ZnM-ZIFs exhibited sizable increase in hydrogen evolution activity as displayed in Fig. 3a. The optimal photocatalytic HER performance occurs in the $\mathrm{Zn}_{0.5} \mathrm{Ni}_{0.5}$-ZIF, achieved $0.92 \mu \mathrm{mol} \mathrm{h}{ }^{-1}$ under UV-Vis light irradiation, which could be comparable to that of $\mathrm{g}-\mathrm{C}_{3} \mathrm{~N}_{4}$ $\left(0.71 \mu \mathrm{mol} \mathrm{h}^{-1}\right)$. Moreover, the photocatalytic HER performance of $\mathrm{Zn}_{0.5} \mathrm{Co}_{0.5}$-ZIF slightly lower than that of the $\mathrm{g}-\mathrm{C}_{3} \mathrm{~N}_{4}$, which 

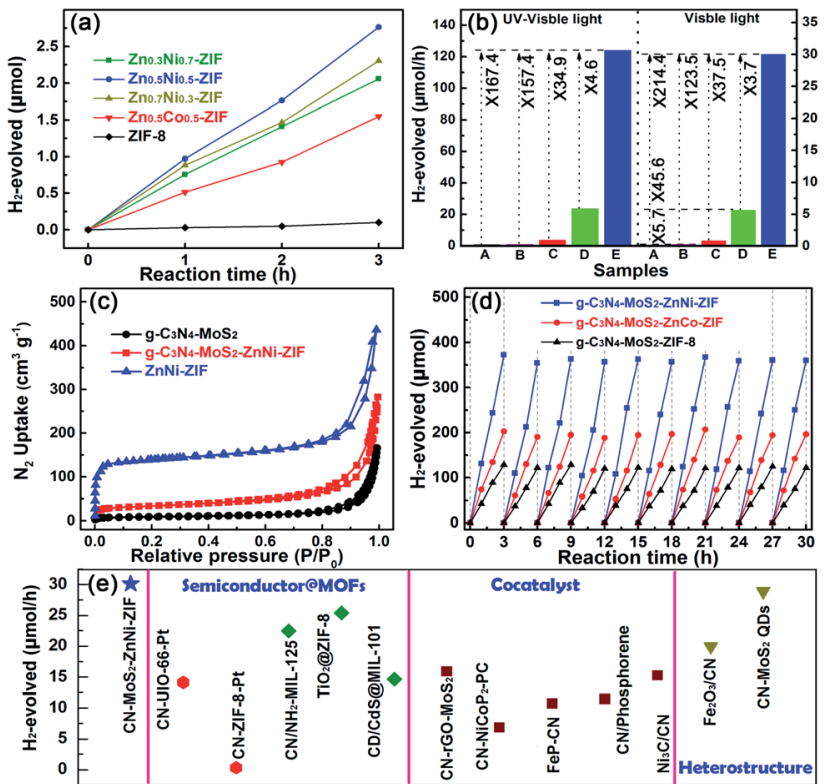

Fig. 3 The photocatalytic $\mathrm{H}_{2}$-production activities of (a) ZnM-ZIF with different molar ratio of $\mathrm{Zn}$ to metals. The comparison results of (b) the photocatalytic hydrogen production activity of the pristine (A) g- $\mathrm{C}_{3} \mathrm{~N}_{4}$, (B) $\mathrm{ZnNi}-\mathrm{ZIF}$, (C) g- $\mathrm{C}_{3} \mathrm{~N}_{4}-\mathrm{ZnNi}-\mathrm{ZIF}$, (D) g- $\mathrm{C}_{3} \mathrm{~N}_{4}-\mathrm{MoS}_{2}$ and (E) ternary $\mathrm{g}-\mathrm{C}_{3} \mathrm{~N}_{4}-\mathrm{MoS}_{2}-\mathrm{ZnNi}$-ZIF under UV-Vis and visible light irradiation. (c) Nitrogen adsorption desorption curve of $\mathrm{g}-\mathrm{C}_{3} \mathrm{~N}_{4}, \mathrm{~g}-\mathrm{C}_{3} \mathrm{~N}_{4}-\mathrm{MoS}_{2}$, $\mathrm{ZnNi}-\mathrm{ZIF}$ and the optimal ternary heterostructure. (d) Photocatalytic $\mathrm{H}_{2}$-production stability of the ternary $\mathrm{g}-\mathrm{C}_{3} \mathrm{~N}_{4}-\mathrm{MoS}_{2}-\mathrm{ZnM}$-ZIFs. (e) Comparison results of the photocatalytic activity of the $\mathrm{g}-\mathrm{C}_{3} \mathrm{~N}_{4}-$ $\mathrm{MoS}_{2}-\mathrm{ZnNi}$-ZIF with the previously reported $\mathrm{g}-\mathrm{C}_{3} \mathrm{~N}_{4}(\mathrm{CN})$ and MOFsbased heterostructures.

was $0.51 \mu \mathrm{mol} \mathrm{h}^{-1}$, which. The photocatalytic HER performance of the CNZN with different weight ratio of ZnNi-ZIF $(\mathrm{Zn}: \mathrm{Ni}=$ $1: 1)$ were compared in Fig. $S 7, \dagger$ the optimal HER performance was obtained in the heterostructure sample containing $10 \mathrm{wt} \%$ ZnNi-ZIF. Notably, the further adoption of the $\mathrm{MoS}_{2}$ (optimal dosage of $6 \mathrm{wt} \%$, Fig. S8†) cocatalyst remarkably improved the photocatalytic HER activity under UV-Vis (Fig. S9a†) and visible light irradiation (Fig. S9b $\dagger$ ).

In order to better evaluate the important role of the $\mathrm{MoS}_{2}$ as well as the ZnM-ZIF, the photocatalytic hydrogen production activity is improved after embedded $\mathrm{g}-\mathrm{C}_{3} \mathrm{~N}_{4}$ with $\mathrm{MoS}_{2}$ and then with ZnM-ZIF. The systematic comparison of photocatalytic hydrogen production activity g- $\mathrm{C}_{3} \mathrm{~N}_{4}, \mathrm{~g}-\mathrm{C}_{3} \mathrm{~N}_{4}-\mathrm{MoS}_{2}$, ZnM-ZIF is showed in Fig. $3 \mathrm{~b}$ and $\mathrm{S} 10 . \dagger$ Under UV-Vis light irradiation, the pristine $\mathrm{g}-\mathrm{C}_{3} \mathrm{~N}_{4}$ and $\mathrm{ZnNi-ZIF}$ exhibited very limited hydrogen production rate of only 0.71 and $0.92 \mu \mathrm{mol} \mathrm{h}{ }^{-1}$, respectively, and the adoption of $\mathrm{MoS}_{2}$ and ZnNi-ZIF both dramatically increased the hydrogen production rate of $\mathrm{g}-\mathrm{C}_{3} \mathrm{~N}_{4}$ due to the utilization and transport efficiency improving of the charge carriers, respectively. Co-embedding of ZnNi-ZIF and $\mathrm{MoS}_{2}$ enhanced the photocatalytic activity of $124.02 \mu \mathrm{mol} \mathrm{h}^{-1}$, which was 167.4 times larger than that of the pristine $g-\mathrm{C}_{3} \mathrm{~N}_{4}$, and was 34.9 and 4.6-fold of that of the $\mathrm{g}-\mathrm{C}_{3} \mathrm{~N}_{4}$ singly loaded with $\mathrm{ZnNi}$ ZIF and $\mathrm{MoS}_{2}$, respectively. Hence, the photocatalytic hydrogen production results proved that the embedding of $\mathrm{ZnNi}-\mathrm{ZIF}$ and
$\mathrm{MoS}_{2}$ showed obvious synergistic effect for increasing the photocatalytic HER activity. Specifically, the CNZN and the CNM exhibited photocatalytic HER performance of 5.7 and 64.2 times larger than that of pristine $\mathrm{g}-\mathrm{C}_{3} \mathrm{~N}_{4}$, indicating the $\mathrm{ZnNi}$ ZIF and $\mathrm{MoS}_{2}$ played an important role on improving the number of exposed active sites and utilization efficiency of the charge carriers, respectively. It was worth noting that the photocatalytic hydrogen production rate of ternary CNMZN, CNMZC and CNMZ was 3.7, 1.9 and 1.2-fold in comparison with sum of photocatalytic hydrogen production of CNM and the corresponding g- $\mathrm{C}_{3} \mathrm{~N}_{4}-\mathrm{ZnM}$-ZIFs (Fig. S10 $\dagger$ ), which confirmed the synergistic effect of the embedding of $\mathrm{MoS}_{2}$ and ZnM-ZIF and facilitate the transportation and utilization efficiency of photo-generated charge carriers.

The large specific surface area, caused by improved number of exposed active sites, was also an important element for the high photocatalytic activity of CNMZN, ${ }^{5,54}$ and the nitrogen adsorption/desorption isotherms (Fig. 3c) was employed to reveal the vital function of ZnNi-ZIF on increasing the porosity of the ternary heterostructure. Adopt $\mathrm{MoS}_{2}$ could increase the specific surface area $\left(S_{\mathrm{BET}}\right)$ of pure $\mathrm{g}-\mathrm{C}_{3} \mathrm{~N}_{4}$ to a certain extent. More obviously, CNMZN exhibited much larger nitrogen uptake and $S_{\mathrm{BET}}$ of $142.73 \mathrm{~m}^{2} \mathrm{~g}^{-1}$ than that of CNM $\left(33.89 \mathrm{~m}^{2} \mathrm{~g}^{-1}\right)$ owing to the highly porous ZnNi-ZIF $\left(501.34 \mathrm{~m}^{2} \mathrm{~g}^{-1}\right)$. In addition to the excellent photocatalytic hydrogen production activity, the CNMZN and ZNMZC exhibited very good photocatalytic stability after $30 \mathrm{~h}$ continuous irradiation (Fig. 3d). In comparison with the pristine ZnM-ZIFs and their heterostructures, the characteristic FTIR peaks of ZnM-ZIF could also be clearly observed in the ZnNi-ZIF and CNMZN heterostructure after the photocatalytic reaction, which further indicated the excellent photocatalytic stability of the ternary CNMZN heterostructure (Fig. S11a $\dagger$ ), and the unchanged FTIR spectra of CNMZ as well as CNMZC were also displayed in Fig. S11b. $\dagger$ To further verify the improved transport, separation and utilization efficiency of the photo-generated charge carrier in $\mathrm{g}-\mathrm{C}_{3} \mathrm{~N}_{4}$ caused by the adoption of $\mathrm{MoS}_{2}$ and ZnM-ZIFs, the photocatalytic hydrogen production performance of the optimal CNMZN $\left(30.1 \mu \mathrm{mol} \mathrm{h}{ }^{-1}\right)$ was compared with the photocatalytic hydrogen production activity of $\mathrm{g}-\mathrm{C}_{3} \mathrm{~N}_{4}$, or MOF-based photocatalysts in previous publication under visible light irradiation. As displayed in Fig. 3e, the optimal CNMZN exhibited very competitive photocatalytic activity in comparison with those of semiconductor-MOFs heterostructures, ${ }^{2,14,35,55-57}$ g- $\mathrm{C}_{3} \mathrm{~N}_{4}$-loaded with different types of cocatalysts, ${ }^{9-11,22,23,54}$ and $\mathrm{g}^{-} \mathrm{C}_{3} \mathrm{~N}_{4}$-based heterostructures. ${ }^{9,58}$

The optimal g- $\mathrm{C}_{3} \mathrm{~N}_{4}-\mathrm{MoS}_{2}-\mathrm{ZnNi}$-ZIF heterostructure exhibited an excellent apparent quantum yield (AQY) value of $22.0 \%$ at $420 \mathrm{~nm}$. The AQY and photocatalytic hydrogen production rate of optimal g- $\mathrm{C}_{3} \mathrm{~N}_{4}-\mathrm{MoS}_{2}-\mathrm{ZnNi}$-ZIF under different specific wavelength illuminations was evaluated and exhibited (Fig. 4a and Table S1 $\dagger$ ) with the irradiation wavelengths of 420, 475, 550 and $650( \pm 8) \mathrm{nm}$, the HER values 18.18, 9.22, 2.76 and 1.42 $\mu \mathrm{mol} \mathrm{h}{ }^{-1}$ (Table S1 $\dagger$ ), respectively, which indicated the HER of the optimal g- $\mathrm{C}_{3} \mathrm{~N}_{4}-\mathrm{MoS}_{2}-\mathrm{ZnNi}$-ZIF (CNMZN) photocatalyst was associated with its UV-visible diffuse reflection spectra, and the electron-promoted photocatalytic hydrogen evolution reaction. 

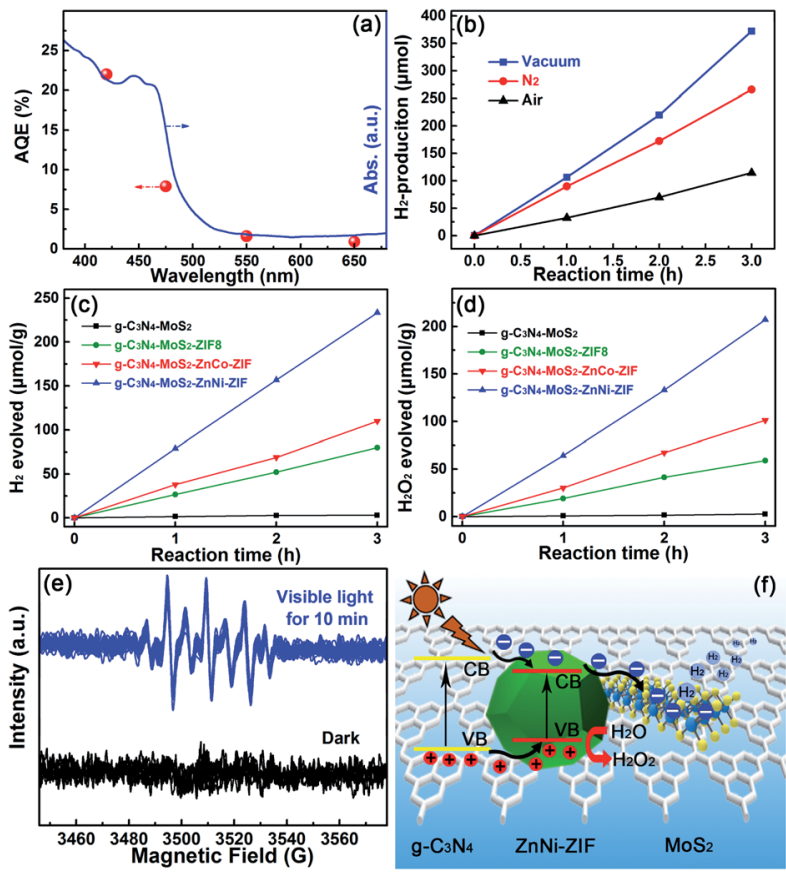

Fig. 4 (a) Wavelength dependence of the apparent quantum efficiencies for the ternary $\mathrm{g}-\mathrm{C}_{3} \mathrm{~N}_{4}-\mathrm{MoS}_{2}-\mathrm{ZnNi}$ - ZIF heterostructures. (b) Photocatalytic $\mathrm{H}_{2}$-evolution rate of the optimal g- $\mathrm{C}_{3} \mathrm{~N}_{4}-\mathrm{MoS}_{2}-\mathrm{ZnNi}-$ ZIF under different atmosphere in TEOA mixture solution. (c) Photocatalytic hydrogen and (d) $\mathrm{H}_{2} \mathrm{O}_{2}$ production activity of the $\mathrm{g}-\mathrm{C}_{3} \mathrm{~N}_{4}-$ $\mathrm{MoS}_{2}-\mathrm{ZnNi}$-ZIF in pure water under UV-Vis light irradiation. (e) EPR responses of the DMPO-OH spin adduct in $\mathrm{g}-\mathrm{C}_{3} \mathrm{~N}_{4}-\mathrm{MoS}_{2}-\mathrm{ZnNi}-\mathrm{ZIF}$. ( $f$ ) Possible separation and utilization mechanism of the photogenerated charge carriers in the optimal $\mathrm{g}-\mathrm{C}_{3} \mathrm{~N}_{4}-\mathrm{MoS}_{2}-\mathrm{ZnNi}-\mathrm{ZIF}$ heterostructure.

Different wavelengths further assured the photocatalytic activity of the optimal g- $\mathrm{C}_{3} \mathrm{~N}_{4}-\mathrm{MoS}_{2}-\mathrm{ZnNi}$-ZIF heterostructure. The considerable photocatalytic hydrogen production in optimal $\mathrm{g}$ $\mathrm{C}_{3} \mathrm{~N}_{4}-\mathrm{MoS}_{2}$-ZnNi-ZIF even with the irradiation wavelengths of $650( \pm 8) \mathrm{nm}$ also verified that $\mathrm{g}-\mathrm{C}_{3} \mathrm{~N}_{4}-\mathrm{MoS}_{2}$ not only acted as the promoter of the charge carriers and high-performance catalyst, but also facilitated the absorption capacity of visible light. These results are consistent with the DRS and PL results of the $\mathrm{g}_{-} \mathrm{C}_{3} \mathrm{~N}_{4}-\mathrm{MoS}_{2}$ and ZnNi-ZIF-based heterostructure.

Under UV-Vis light irradiation the photocatalytic hydrogen production of the optimal ternary CNMZN heterostructure was evaluated at different atmosphere for comprehensively assessing its practical applications value (Fig. $4 \mathrm{~b}$ ). The photocatalytic HER activity of the optimal ternary heterostructure under $\mathrm{N}_{2}$ atmosphere decreased slightly due to the easier hydrogen release under vacuum. It should be noted that even in air atmosphere with oxygen facilitating the backward reaction, ${ }^{13}$ the optimal CNMZN exhibited considerably photocatalytic hydrogen evolution activity, this result revealed that the CNMZN ternary heterostructure was suitable for practical applications.

Impressively, as demonstrated in Fig. 4c, sharp contrast to the very weak hydrogen evolution of the $\mathrm{g}-\mathrm{C}_{3} \mathrm{~N}_{4}-\mathrm{MoS}_{2}$ without sacrificial agent (pure water), the CNMZ, CNMZC and CNMZN ternary heterostructures exhibited considerable $\mathrm{H}_{2}$-evolution performance of 26.7, 36.6 and $77.8 \mu \mathrm{mol} \mathrm{h}^{-1} \mathrm{~g}^{-1}$ under UV-Vis light irradiation with the considerable $\mathrm{H}_{2} \mathrm{O}_{2}$ production rate (Fig. 4d). For deeply investigate the formation process of $\mathrm{H}_{2} \mathrm{O}_{2}$, using 5,5-dimethyl-1-pyrroline N-oxide (DMPO) as the spin trapping agent, Electron Paramagnetic Resonance (EPR) responses were adopted to test the oxidation products during the photocatalytic reaction in pure water of CNMZN. As exhibited in Fig. 4e, the characteristic signals of $-\mathrm{OH}$ could be observed in the DMPO aqueous solution after the visible light irradiation, indicating the formation of $-\mathrm{OH}$ through singe electron oxidation of water. On the base of the above-mentioned band structure and photocatalytic activity results, the mechanism of action of photo-exited charge carriers in the CNMZN photocatalyst was proposed in Fig. 4f.

The photo-induced electrons transferred from the $\mathrm{CB}$ of $\mathrm{g}$ $\mathrm{C}_{3} \mathrm{~N}_{4}$ and ZnNi-ZIFs to that of $\mathrm{MoS}_{2}$, being beneficial for the photocatalytic hydrogen production owing to the low HER overpotential and large current density of $\mathrm{MoS}_{2}$. Simultaneously, the photo-exited holes were transferred into the VB of ZnNi-ZIF, where the holes could be timely consumed by sacrificial agent due to the highly porous morphology of the $\mathrm{ZnNi}$ ZIF. For investigating the important role of ZnM-ZIF and/or $\mathrm{MoS}_{2}$ on suppressing the recombination of the photogenerated electron-hole pairs of the $\mathrm{g}_{-} \mathrm{C}_{3} \mathrm{~N}_{4}$ based heterostructure, the room temperature photoluminescence (PL) spectra excited at $360 \mathrm{~nm}$ (Fig. 5a) was employed. In contrast to the very strong PL peak of the pristine $\mathrm{g}-\mathrm{C}_{3} \mathrm{~N}_{4}$ (around $450 \mathrm{~nm}$ ), the dramatically quenched PL signals were observed against the $\mathrm{g}^{-} \mathrm{C}_{3} \mathrm{~N}_{4}-\mathrm{ZnM}-\mathrm{ZIF}(\mathrm{M}=\mathrm{Co}, \mathrm{Cu}, \mathrm{Ni}$ ) and $\mathrm{CNM}$ (Fig. S12 $\dagger$ ), owing to
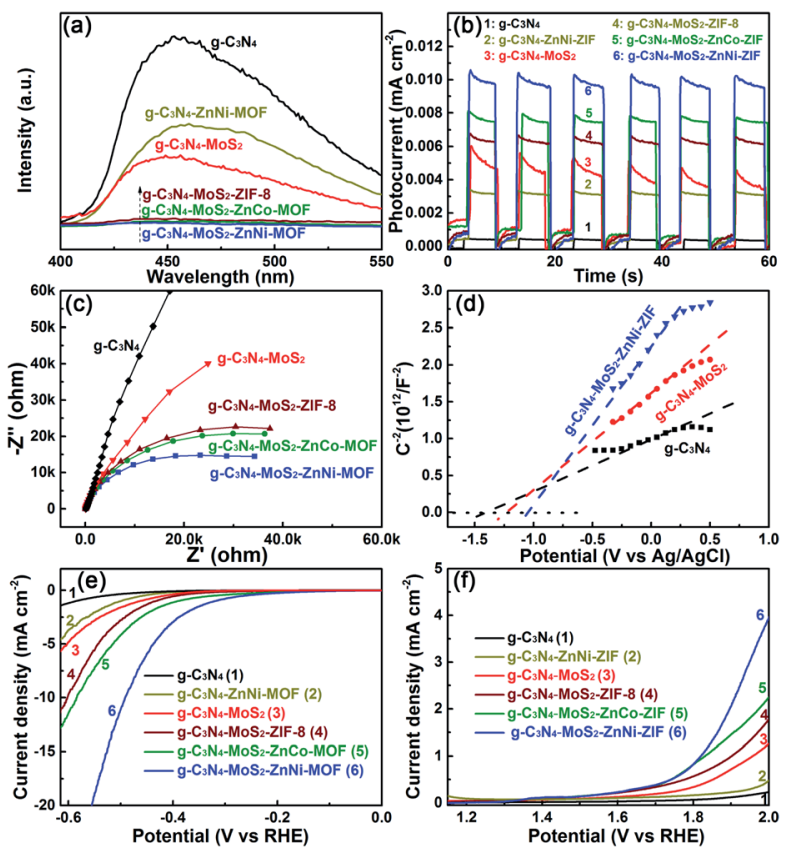

Fig. 5 Effect of different type ZnM-ZIF and the adoption of $\mathrm{MoS}_{2}$ on (a) the PL emission spectra, (b) transient photocurrent responses, (c) EIS spectra, (d) the Mott-Schottky plots, and electrocatalytic (e) HER and (f) OER response of the $\mathrm{g}-\mathrm{C}_{3} \mathrm{~N}_{4}$-based heterostructures. 
the increased porosity and separation as well as utilization efficiency of the charge carriers, respectively and the relative order of PL peaks for $\mathrm{g}-\mathrm{C}_{3} \mathrm{~N}_{4}-\mathrm{ZnM}$-ZIF samples was found to be; g- $\mathrm{C}_{3} \mathrm{~N}_{4}>\mathrm{g}-\mathrm{C}_{3} \mathrm{~N}_{4}-\mathrm{ZnCo}>\mathrm{g}-\mathrm{C}_{3} \mathrm{~N}_{4}-\mathrm{ZnCu}>\mathrm{g}-\mathrm{C}_{3} \mathrm{~N}_{4}-\mathrm{ZnNi}$. Notably, the ternary samples, co-embedded with ZnM-ZIF and $\mathrm{MoS}_{2}$, showed very weak PL peaks, and the relative order of PL response intensity for the samples with different types of ZnMZIF was found to be: CNMZ > CNMZC > CNMZN, which was consistent with the trend of the photocatalytic hydrogen evolution activity.

The $\mathrm{g}-\mathrm{C}_{3} \mathrm{~N}_{4}$ based photocatalysts were investigated through the transient photocurrent and electrochemical impedance spectroscopy (EIS) measurements to explore the transport and excitation behavior of the photo-exited charge carriers. As shown in Fig. 5b, with the repeated on/off cycles of UV-Vis light irradiation, all the $\mathrm{g}-\mathrm{C}_{3} \mathrm{~N}_{4}$ based samples exhibited the steady and reproducible photocurrent responses. The rapid recombination of charge carriers made the photocurrent density of the pristine $\mathrm{g}-\mathrm{C}_{3} \mathrm{~N}_{4}$ very weak. Both the $\mathrm{g}-\mathrm{C}_{3} \mathrm{~N}_{4}-\mathrm{ZnM}-\mathrm{ZIF}$ (Fig. S13†) and CNM demonstrated stronger photocurrent response owing to the increased specific surface area and separation as well rapid consumed electrons, respectively. The relative order for the photocurrent density for the $\mathrm{g}-\mathrm{C}_{3} \mathrm{~N}_{4}-\mathrm{ZnM}-\mathrm{ZIF}$ samples was found to be; g- $\mathrm{C}_{3} \mathrm{~N}_{4}>\mathrm{g}-\mathrm{C}_{3} \mathrm{~N}_{4}-\mathrm{ZnCo}>\mathrm{g}-\mathrm{C}_{3} \mathrm{~N}_{4}-\mathrm{ZnCu}>\mathrm{g}-\mathrm{C}_{3} \mathrm{~N}_{4}-$ $\mathrm{ZnNi}$, which showed that after incorporation of ZnM-ZIF (M = $\mathrm{Cu}, \mathrm{Co}, \mathrm{Ni})$ the photocurrent density increase that was consistent with photocatalytic HER activity. Impressively, for the ternary heterostructure, the co-loading of ZnM-ZIF and $\mathrm{MoS}_{2}$ exhibited the synergistic effect for facilitating the photocurrent response, and the value of the photo-current for the ternary heterostructures with different type of ZnM-ZIF was consistent with the photocatalytic HER activity.

The EIS results of the $\mathrm{g}-\mathrm{C}_{3} \mathrm{~N}_{4}$, ZnM-ZIF g- $\mathrm{C}_{3} \mathrm{~N}_{4}-\mathrm{ZnM}-\mathrm{ZIF}$ and g- $\mathrm{C}_{3} \mathrm{~N}_{4}-\mathrm{MoS}_{2}-\mathrm{ZnM}$-ZIF were exhibited in Fig. $5 \mathrm{c}$, the ternary g$\mathrm{C}_{3} \mathrm{~N}_{4}-\mathrm{MoS}_{2}-\mathrm{ZnM}$-ZIF displayed much smaller semicircle radius than that of and pristine $\mathrm{g}-\mathrm{C}_{3} \mathrm{~N}_{4}$, ZnNi-ZIF, g- $\mathrm{C}_{3} \mathrm{~N}_{4}-\mathrm{ZnCo}-\mathrm{ZIF}$ and $\mathrm{g}_{-} \mathrm{C}_{3} \mathrm{~N}_{4}-\mathrm{ZnCu}-\mathrm{ZIF}$ (Fig. S14 $\dagger$ ), indicating that the interfacial transfer of the charge carriers was dramatically enhanced as verified by the smaller arc radius, which is normally the evidence of a lower electron transfer resistance. Notably, the CNMZN owning the optimal photocatalytic HER performance showed the smallest arc radius. In addition, the hydrogen evolution behaviors were evaluated by the Mott-Schottky plots and electrocatalytic HER and OER measurements. As depicted in Fig. 5d, the CNM displayed a more negative flat-band potentials than that of the pristine $\mathrm{g}-\mathrm{C}_{3} \mathrm{~N}_{4}$, indicating its improved reduction capacity. Notably, after the embedding of ZnM-ZIF, the sample exhibited higher reduction capacity as confirmed by their further upward shift in the flat-band potential, and the CNMZN with the optimal photocatalytic activity possessed the most negative flat-band potential. It was extensively reported that the cocatalyst with low electrocatalytic HER and/or oxygen evolution reaction (OER) overpotential and high current density could boost the utilization efficiency of charge carriers, thereby improve the photocatalytic activity. Moreover, the HER and OER cocatalyst could play a synergistic effect by co-loading to enhance the photocatalytic activity. ${ }^{59}$ The
HER and OER capacity of the $\mathrm{g}-\mathrm{C}_{3} \mathrm{~N}_{4}$-based heterostructure with $\mathrm{MoS}_{2}$ and/or ZnM-ZIF were evaluated using HER and OER measurements. As could be observed from Fig. 5e and $f$, the embedding of both $\mathrm{MoS}_{2}$ and ZnNi-ZIF could dramatically promote the electrocatalytic HER and OER performance, and the co-embedding of $\mathrm{MoS}_{2}$ and $\mathrm{ZnM}$-ZIF over $\mathrm{g}-\mathrm{C}_{3} \mathrm{~N}_{4}$ further facilitated the electrocatalytic HER and OER performance, and the ternary CNMZN displayed the smallest HER and OER overpotential, and the largest current density, being consistent with the photocatalytic HER performance of the g-C $\mathrm{N}_{4}-\mathrm{MoS}_{2}-$ ZnM-ZIFs.

\section{Conclusions}

Herein, we have successfully designed and fabricated various bimetallic zeolite imidazole framework (ZnM-ZIF, M = Co, Ni) as the photocatalytic hydrogen production catalyst with considerable photocatalytic HER activity. Furthermore, photocatalytic HER activity of zeolite imidazole framework (ZnM$\mathrm{ZIF}, \mathrm{M}=\mathrm{Co}$, Ni) was enhanced by the introduction of $\mathrm{g}-\mathrm{C}_{3} \mathrm{~N}_{4}-$ $\mathrm{MoS}_{2}$ 2D-2D heterostructure. g- $\mathrm{C}_{3} \mathrm{~N}_{4}-\mathrm{MoS}_{2}$ 2D-2D heterostructure facilitate the separation as well as utilization efficiency of the photo-generated charge carriers due to the lower HER flat-band potential of $\mathrm{MoS}_{2}$. ZnM-MOF not only inhibited the aggregation of the CNM heterostructure, but also further improved the separation and transport efficiency of the charge carriers in the ternary g- $\mathrm{C}_{3} \mathrm{~N}_{4}-\mathrm{MoS}_{2}-\mathrm{ZnM}-\mathrm{ZIF}$. Consequently, the optimal $\mathrm{g}-\mathrm{C}_{3} \mathrm{~N}_{4}-\mathrm{MoS}_{2}-\mathrm{ZnNi}$-ZIF exhibited the extraordinary photocatalytic HER activity, which is $214.4,37.5$, and 3.7 times larger than that of the pristine $\mathrm{g}-\mathrm{C}_{3} \mathrm{~N}_{4}, \mathrm{~g}-\mathrm{C}_{3} \mathrm{~N}_{4}-\mathrm{ZnNi}-\mathrm{ZIF}$ and $\mathrm{g}$ $\mathrm{C}_{3} \mathrm{~N}_{4}-\mathrm{MoS}_{2}$, respectively, and exhibited a $\mathrm{H}_{2}$-evolution performance of $77.8 \mu \mathrm{mol} \mathrm{h} \mathrm{h}^{-1} \mathrm{~g}^{-1}$ under UV-Vis light irradiation coupled with oxidation of $\mathrm{H}_{2} \mathrm{O}$ into $\mathrm{H}_{2} \mathrm{O}_{2}$. This work would furnish an innovative path for MOF candidate and open a new method for the better utilization of porous MOF-based heterostructure for photocatalyst.

\section{Conflicts of interest}

There are no conflicts to declare.

\section{Acknowledgements}

This work was financially supported by the National Natural Science Foundation of China (NSFC) (No. 22071081, 21601063), and the Opening Project of Key Laboratory of Inorganic Functional Materials and Devices, Chinese Academy of Sciences (Grant No. KLIFMD202007).

\section{Notes and references}

1 M. Lu, J. Liu, Q. Li, M. Zhang, M. Liu, J. L. Wang, D. Q. Yuan and Y. Q. Lan, Angew. Chem., Int. Ed., 2019, 131, 1252212527.

2 X.-B. Meng, J.-L. Sheng, H.-L. Tang, X.-J. Sun, H. Dong and F.-M. Zhang, Appl. Catal., B, 2019, 244, 340-346. 
3 F. M. Zhang, J. L. Sheng, Z. D. Yang, X. J. Sun, H. L. Tang, M. Lu, H. Dong, F. C. Shen, J. Liu and Y. Q. Lan, Angew. Chem., Int. Ed., 2018, 57, 12106-12110.

4 J.-H. Zhao, L.-W. Liu, K. Li, T. Li and F.-T. Liu, CrystEngComm, 2019, 21, 2416-2421.

5 Y.-Z. Lin, K. Wang, Y. Zhang, Y.-C. Dou, Y.-J. Yang, M.-L. Xu, Y. Wang, F.-T. Liu and K. Li, J. Mater. Chem. C, 2020, 8, 10071-10077.

6 S. C. Shit, I. Shown, R. Paul, K.-H. Chen, J. Mondal and L.-C. Chen, Nanoscale, 2020, 12, 23301-23332.

7 X. Ning and G. Lu, Nanoscale, 2020, 12, 1213-1223.

8 Y. Zhang, Y.-Z. Lin, Z.-X. Wang, K. Li, T. Li and F.-T. Liu, Catal. Sci. Technol., 2019, 9, 583-587.

9 Y.-J. Yuan, Y. Yang, Z. Li, D. Chen, S. Wu, G. Fang, W. Bai, M. Ding, L.-X. Yang and D.-P. Cao, ACS Appl. Energy Mater., 2018, 1, 1400-1407.

10 J. Ran, W. Guo, H. Wang, B. Zhu, J. Yu and S. Z. Qiao, Adv. Mater., 2018, 30, 1800128.

11 K. He, J. Xie, Z.-Q. Liu, N. Li, X. Chen, J. Hu and X. Li, J. Mater. Chem. A, 2018, 6, 13110-13122.

12 L. Zhao, Z. Zhao, Y. Li, X. Chu, Z. Li, Y. Qu, L. Bai and L. Jing, Nanoscale, 2020, 12, 10010-10018.

13 K. Li, M. Han, R. Chen, S. L. Li, S. L. Xie, C. Mao, X. Bu, X. L. Cao, L. Z. Dong and P. Feng, Adv. Mater., 2016, 28, 8906-8911.

14 R. Wang, L. Gu, J. Zhou, X. Liu, F. Teng, C. Li, Y. Shen and Y. Yuan, Adv. Mater. Interfaces, 2015, 2, 1500037.

15 Y.-P. Zhang, H.-L. Tang, H. Dong, M.-Y. Gao, C.-C. Li, X.-J. Sun, J.-Z. Wei, Y. Qu, Z.-J. Li and F.-M. Zhang, J. Mater. Chem. A, 2020, 8, 4334-4340.

16 Z. Zhang, L. Bai, Z. Li, Y. Qu and L. Jing, J. Mater. Chem. A, 2019, 7, 10879-10897.

17 L. Zhang, G. Wang and Z. Jin, New J. Chem., 2019, 43, 64116421.

18 T. Li, J.-D. Cui, Y.-Z. Lin, K. Liu, R. Li, B. Wang, H. Xie and K. Li, New J. Chem., 2020, 45, 162-168.

19 J. Zheng, B. Zhang and Z. Wang, RSC Adv., 2021, 11, 78-86.

$20 \mathrm{~J}$. Liu and E. Hua, RSC Adv., 2020, 10, 5260-5267.

21 L. Liu, X. Song, X. Kong, Q. Duan and E. Zhu, RSC Adv., 2020, 10, 9116-9125.

22 D. Zeng, T. Zhou, W.-J. Ong, M. Wu, X. Duan, W. Xu, Y. Chen, Y.-A. Zhu and D.-L. Peng, ACS Appl. Mater. Interfaces, 2019, 11, 5651-5660.

23 K. Li, Y.-Z. Lin, K. Wang, Y. Wang, Y. Zhang, Y. Zhang and F.-T. Liu, Appl. Catal., B, 2020, 268, 118402.

24 Y.-H. Luo, L.-Z. Dong, J. Liu, S.-L. Li and Y.-Q. Lan, Coord. Chem. Rev., 2019, 390, 86-126.

25 B. Zhu, R. Zou and Q. Xu, Adv. Mater., 2018, 8, 1801193.

26 L. Jiao, Y. Wang, H. L. Jiang and Q. Xu, Adv. Mater., 2018, 30, 1703663.

27 N. Li, J. Liu, J. J. Liu, L. Z. Dong, Z. F. Xin, Y. L. Teng and Y. Q. Lan, Angew. Chem., Int. Ed., 2019, 131, 5280-5285.

28 L. Z. Dong, L. Zhang, J. Liu, Q. Huang, M. Lu, W. X. Ji and Y. Q. Lan, Angew. Chem., Int. Ed., 2020, 132, 2681-2685.

29 Y.-C. Qiu, S. Yuan, X.-X. Li, D.-Y. Du, C. Wang, J.-S. Qin, H. F. Drake, Y.-Q. Lan, L. Jiang and H.-C. Zhou, J. Am. Chem. Soc., 2019, 141, 13841-13848.
30 C. Li, H. Xu, J. Gao, W. Du, L. Shangguan, X. Zhang, R.-B. Lin, H. Wu, W. Zhou and X. Liu, J. Mater. Chem. A, 2019, 7, 1192811933.

31 M. Taddei, G. M. Schukraft, M. E. Warwick, D. Tiana, M. J. McPherson, D. R. Jones and C. Petit, J. Mater. Chem. A, 2019, 7, 23781-23786.

32 Y. Z. Chen, C. Wang, Z. Y. Wu, Y. Xiong, Q. Xu, S. H. Yu and H. L. Jiang, Adv. Mater., 2015, 27, 5010-5016.

33 J.-H. Zhao, Y. Wang, X. Tang, Y.-H. Li, F.-T. Liu, Y. Zhang and K. Li, Dalton Trans., 2019, 48, 3560-3565.

34 M. Zhang, Q. Shang, Y. Wan, Q. Cheng, G. Liao and Z. Pan, Appl. Catal., B, 2019, 241, 149-158.

35 K. Li, Y. Zhang, Y.-Z. Lin, K. Wang and F.-T. Liu, ACS Appl. Mater. Interfaces, 2019, 11, 28918-28927.

36 C. Li, H. Wu, Y. Du, S. Xi, H. Dong, S. Wang and Y. Wang, ACS Sustainable Chem. Eng., 2020, 8, 12934-12943.

37 T. Li, J.-D. Cui, M.-L. Xu, R. Li, L.-M. Gao, P.-L. Zhu, H.-Q. Xie and K. Li, CrystEngComm, 2020, 22, 5620-5627.

38 R. Shen, J. Xie, H. Zhang, A. Zhang, X. Chen and X. Li, ACS Sustainable Chem. Eng., 2018, 6, 816-826.

39 S. Borthakur, P. Basyach, L. Kalita, K. Sonowal, A. Tiwari, P. Chetia and L. Saikia, New J. Chem., 2020, 44, 2947-2960.

40 V. Shanmugam, K. S. Jeyaperumal, P. Mariappan and A. L. Muppudathi, New J. Chem., 2020, 44, 13182-13194.

41 M. Guan, C. Wang, S. Li, H. Du and Y. Yuan, ACS Sustainable Chem. Eng., 2020, 8, 10313-10320.

42 L. Lin, Z. Yu and X. Wang, Angew. Chem., Int. Ed., 2019, 131, 6225-6236.

43 L.-Z. Qin, Y.-Z. Lin, Y.-C. Dou, Y.-J. Yang, K. Li, T. Li and F. Liu, Nanoscale, 2020, 12, 13829-13837.

44 H. J. Kong, K.-H. Kim, S. Kim, H. Lee and J. K. Kang, J. Mater. Chem. A, 2019, 7, 26279-26284.

45 T. Chen, D. Yin, F. Zhao, K. K. Kyu, B. Liu, D. Chen, K. Huang, L. Deng and L. Li, New J. Chem., 2019, 43, 463-473.

46 Y. Zeng, Y. Xia, W. Song and S. Luo, J. Mater. Chem. A, 2019, 7, 25908-25914.

47 T. Li, J.-D. Cui, L.-M. Gao, Y.-Z. Lin, R. Li, H. Xie, Y. Zhang and K. Li, ACS Sustainable Chem. Eng., 2020, 8, 13352-13361.

48 Z. Zhao, S. Luo, P. Ma, Y. Luo, W. Wu, Y. Long and J. Ma, ACS Sustainable Chem. Eng., 2020, 8, 8814-8822.

49 K. Li, Y.-Z. Lin, Y. Zhang, M.-L. Xu, L.-W. Liu and F.-T. Liu, J. Mater. Chem. C, 2019, 7, 13211-13217.

50 H. Su, M. Liu, W. Cheng, X. Zhao, F. Hu and Q. Liu, J. Mater. Chem. A, 2019, 7, 11170-11176.

51 Y. J. Tang, Y. Wang, X. L. Wang, S. L. Li, W. Huang, L. Z. Dong, C. H. Liu, Y. F. Li and Y. Q. Lan, Adv. Mater., 2016, 6, 1600116.

52 X. Zeng, L. Huang, C. Wang, J. Wang, J. Li and X. Luo, ACS Appl. Mater. Interfaces, 2016, 8, 20274-20282.

53 L. Kong, J. Yan and S. F. Liu, ACS Sustainable Chem. Eng., 2018, 7, 1389-1398.

54 K. Li, R. Chen, S.-L. Li, S.-L. Xie, X.-L. Cao, L.-Z. Dong, J.-C. Bao and Y.-Q. Lan, ACS Appl. Mater. Interfaces, 2016, 8, 4516-4522.

55 C.-C. Wang, X.-H. Yi and P. Wang, Appl. Catal., B, 2019, 247, 24-48. 
56 L. Tian, X. Yang, Q. Liu, F. Qu and H. Tang, Appl. Surf. Sci., 2018, 455, 403-409.

57 G. Zhou, M.-F. Wu, Q.-J. Xing, F. Li, H. Liu, X.-B. Luo, J.-P. Zou, J.-M. Luo and A.-Q. Zhang, Appl. Catal., B, 2018, 220, 607-614.
58 Q. Xu, B. Zhu, C. Jiang, B. Cheng and J. Yu, Sol. RRL, 2018, 2, 1800006.

59 J. Yang, D. Wang, H. Han and C. Li, Acc. Chem. Res., 2013, 46, 1900-1909. 